Bangl. J. Vet. Med. (2009). 7(1) : $287-292$

\title{
PREVALENCE AND PATHOLOGY OF ARTHROPOD INFESTATION IN DOMESTIC AND STRAY
} CATS IN BANGLADESH

\author{
S.A. $\operatorname{Rahman}^{1}$ *, M. J. Islam ${ }^{1}$, N. Begum ${ }^{1}$, M.A. Ali ${ }^{1}$ and A.S.M. Bari ${ }^{2}$ \\ ${ }^{1}$ Department of Parasitology, Faculty of Veterinary Science, Bangladesh Agricultural University, Mymensingh - \\ 2202, 르라. \\ Mymensingh - 2202, Bangladesh
}

\begin{abstract}
This study was designed to determine the prevalence and pathology of potential arthropods of the domestic and stray cats (Felis catus) that had not received veterinary care and had no known exposure to insecticide application and other form of medication. In doing so, 36 domestic and stray cats were taken from Mymensingh district, Bangladesh. The research work was carried out during the period of July 2006 to June 2007 in Mymensingh district, Bangladesh. In the 36 examined cats, overall 32 (88.89\%) cats had arthropod infestation. The rate of infestation was Ctenocephalides felis felis, 86\% (31 out of 36), Demodex cati, 11\% (4 out of 36) and Linguatula serrata, 14 \% (5 out of 36). Slightly higher rate of Ct. felis felis infestation was found in kittens (90\%) followed by adults $(84.61 \%)$. There was similar age prevalence of $D$. cati and $L$. serrata infection in kittens and adults. Females (90\%) were 2.07 times more susceptible to Ct. felis felis infestation than males (81.25\%). The rate of arthropod infection did not vary greatly over seasons. But in L. serrata infection, there was higher prevalence in summer (27.27\%) than rainy (11.11\%) and winter (6.25\%) seasons. Grossly, demodectic mange was characterized by alopecia, epidermal scaling, scab formation and denudation of the skin mostly found in the ear and the neck. The legs and the abdomen were also affected. At histopathology, sections of mite were found in the hair follicles of the skin along with folliculitis (two cases). Pneumonia was found both grossly and microscopically in lungs of five cats but it was very difficult to correlate with the presence of small number of $L$. serrata organisms.
\end{abstract}

Key words: Arthropod, prevalence, pathology, domestic and stray cat

\section{INTRODUCTION}

Arthropod infestation is common in cats. Arthropod infestation can lead to life threatening anemia in young and debilitated cats. Arthropods are capable of disease transmission (Soulsby, 1982). Cat fleas cause minute papules and pruritus as a result of flea hypersensitivity that is known as "military dermatitis" (Thoday, 1979). Besides, cat fleas are responsible for severe asthmatic problem in human when cat and human live in the same living room (Jacobs, 1985). Demodecosis lead to alopecia, thickened and wrinkled skin with a "mousy odor" in cats (Jacobs, 1985). The adults of L. serrata apparently feed on respiratory mucosal cells and blood and cause impairment of respiration and obstruction of the nasal passages in carnivores. People living in the Middle East, India, Africa, Southeast Asia, and the East Indies are sometimes infected with the larvae of L. serrata by eating raw glands of cattle, sheep, and goats that have the larvae. People may suffer from irritation in their nose and throat. Deaths have been reported due to blocked air passages (Bowman, 2000). In addition, Kelly et al. (2005) and Shaw et al. (2004) noticed that cat fleas served as carriers of emerging human pathogens, Rickettsia felis, Bartonella henselae and $B$. clarridgeie in New Zealand and in the UK respectively.

In Bangladesh, there is no published report on the prevalence and pathology of arthropod infestation in domestic and stray cats. Thus, an attempt was made to find out the occurrence of arthropods in relation to their age, sex, and season and to show the gross and microscopic changes produced by the parasites.

\section{MATERIALS AND METHODS}

The study was carried out from July, 2006 to June, 2007 in Mymensingh district, Bangladesh. A total of 36 domestic and stray cats (indigenous breed) were collected from Mymensingh district, Bangladesh. The experiment was based on direct examination of the skin, skin scrapings, fecal, autopsy and histopathological examination. Ectoparasites were

\footnotetext{
*Corresponding author’s e-mail: s.arafatur.rahman.edu@gmail.com 


\section{S.A. Rahman and others}

collected by hand picking and by using tools. In case of fleas, a flea comb and in case of lice a brush and a lice comb were used. Skin scrapings were taken from the suspected areas by using glycerinized scalpel until oozing for recovery of mites. The scrapings were boiled gently by adding $10 \%$ potassium hydroxide and examined under microscope using 10x magnification (Hendrix and Robinson, 2006). Fecal samples (10-15g) were taken from freshly voided fecal pad early in the morning. Fecal examinations were performed by following direct smear and concentration techniques (Soulsby, 1982). The respiratory tracts of dead or euthanized cats were examined thoroughly for detection of gross lesions and collection of parasites. The collected arthropod parasites were preserved in glycerin alcohol in separate vials for each host. Permanent slides of arthropods were prepared according to the procedure described by Cable (1957). Arthropods were identified by using keys and description given by Soulsby (1982) and Wall and Shearer (1997). The skin of the cats was examined thoroughly for gross lesions. Suspected parts of the skin and respiratory tracts were collected. The collected parts were sent for histopathological study as per standard method (Luna, 1968).

The prevalence of ectoparasites was computed by using formula described by Thrushfield (1995). Odds ratio was calculated by using formula given by Schlesselman (1982).

\section{RESULTS AND DISCUSSION}

Overall 32 (out of 36) cats (88.89\%) were infected with one or two or three species of arthropods (Table 1). This finding is in conformity with earlier finding of Akucewich et al. (2002) in the USA who found $92.5 \%$ flea infestation in cats. On the other hand, Rataj et al. (2004) in Slovenia documented 34. 65\% cats were infested with mites and lice. In this study, recorded species were Ct. felis felis (86\%), D. cati (11\%) and L. serrata (14\%) (Table 1). These findings are similar to that of Cruz et al. (2001) in Mexico, Visser et al. (2001) in Germany and Koutinas et al. (1995) who recorded 92.3\%, 91.6\%, and 97.4\% Ct. felis felis infestation respectively in cats. On the other hand, Shaikh and Huq (1984) in Bangladesh and Coman et al. (1981) in Australia detected $51.4 \%$ and $16 \%$ prevalence of Ct. felis respectively in cats. A few data is available to explain the prevalence of Demodex sp. infection in cats. However, Samad et al. (1979) found demodectic mange in cattle in Bangladesh. Vecchio and Abramo (1999) reported $D$. cati in a cat from Italy. On the other hand, Sotiraki et al. (2001) found no D. cati from 161 cats in Greece. In case of $L$. serrata infection, Altas and Tasan (1999) found $1.43 \%$ prevalence of $L$. serrata in cats from Turkey. Rahman et al. (1971) found $45 \%$ prevalence of $L$. serrata from dogs in Bangladesh. $L$. serrrata nymph from cattle and goats of Bangladesh was recorded by Rahman et al. (1980). Immature linguatulosis in a Murrah buffalo was reported from Bangladesh by Chowdhury and Dewan (1967). Soulsby (1982) stated that animals having poor condition or chronic debilitating disease are more susceptible to flea infestation. Vecchio and Abramo (1999) found D. cati infection in a cat with feline immunodeficiency virus in Italy. In this experiment, the collected cats had poor health. So overall higher rate of infection could be due to poor health, poor hygienic condition, immunosuppressive diseases, breed of cats, environmental factors and method of study.

Demodectic mange was detected on the skin of two (5.55\%) cats. Grossly, the lesions were characterized by alopecia, epidermal scaling, scab formation and denudation of the skin. The lesions mostly found in the skin of the ear and neck (Figure 1). The legs and abdomen were also affected. At histopathology, sections of mite were found in the hair follicles of the skin. There was evidence of folliculitis characterized by perifollicular infiltration of neutrophils and lymphocytes (Figure 2). These findings are similar to the description given by Jones et al. (1996) and Soulsby (1982). In five cases, pneumonia was found both grossly and microscopically. At post-mortem examination, the lungs parenchyma showed intense hemorrhage and congestion in all the cases but in two cases small white spots were found on the surface of the lungs (Figure 4). Microscopically, there were interstitial pneumonia characterized by thickening of inter-alveolar septa and some alveoli were filled with exudates containing mononuclear cells (Figure 5). But these lesions in the lungs are very difficult to correlate with the presence of small number of $L$. serrata organisms. In this experiment only pathological and parasitological examination was done. If microbial and other tests were done then confirmed cause of pneumonia could have identified. 
Arthropod infestation in domestic and stray cats

Table 1. Prevalence and pathology of arthropod infestation in cats $(n=36)$ in Bangladesh

\begin{tabular}{|c|c|c|c|c|c|}
\hline \multirow{2}{*}{$\begin{array}{l}\text { Arthropod } \\
\text { species }\end{array}$} & \multicolumn{2}{|c|}{ Prevalence } & \multicolumn{2}{|c|}{ Parasite burden } & \multirow[t]{2}{*}{ Location in the host } \\
\hline & $\begin{array}{l}\text { No. of cats } \\
\text { infected }\end{array}$ & $\begin{array}{l}\text { Percentage (\%) of } \\
\text { infected cats }\end{array}$ & Range & Mean \pm SD & \\
\hline Ct. felis felis & 31 & $86 \%$ & $\begin{array}{c}1-7 \text { (per } \\
\text { square inch) }\end{array}$ & $35.1 \pm 66.7$ & Skin \\
\hline D. cati & 4 & $11 \%$ & $\begin{array}{c}1-3 \text { (per } \\
\text { focus) }\end{array}$ & & Skin (hair follicles) \\
\hline L. serrata & 5 & $14 \%$ & $1-4$ & $2.25 \pm 1.5$ & Larynx to lungs \\
\hline Overall & 32 & $88.89 \%$ & & & \\
\hline $\begin{array}{c}\text { Parasite } \\
\text { identified }\end{array}$ & $\begin{array}{l}\text { Organ } \\
\text { affected }\end{array}$ & $\begin{array}{l}\text { Pathological } \\
\text { condition }\end{array}$ & $\begin{array}{l}\text { No. of cats } \\
\text { affected }\end{array}$ & \multicolumn{2}{|c|}{ Percentages (\%) of infection } \\
\hline D. cati & Skin & Demodectic mange & 2 & & $.55 \%$ \\
\hline
\end{tabular}

$\mathrm{n}=$ Total number of cats examined, SD = Standard Deviation

In case of Ct. felis felis infestation, higher prevalence was recorded in kittens (90\%) than adult cats (84.61 \%). In $D$. cati infestation, $10 \%$ kittens were affected whereas the rate is $11.53 \%$ in adults. Slightly higher infection rate was found in adults (15.38\%) followed by kittens (10\%) in L. serrata infection. (Table 2). Similar findings were stated by Vecchio and Abramo (1999) and Soulsby (1982). Soulsby (1982) stated that flea infestation was more common in older cats and demodecosis was evident after 3-9 months in dogs. Vecchio and Abramo (1999) described a 10 year old cat with demodecosis in Italy. Age prevalence of $L$. serrata can not be compared due to paucity of relevant literature. Slightly higher prevalence of Ct. felis felis infection in kittens may be due to frequent contact with their mothers. Moreover, the variation in the prevalence of infection may be due to certain immunological phenomena, source of infection and such other factors.

Table 2. Age prevalence of Ct. felis felis, D. cati and L. serrata in the cats of Bangladesh

\begin{tabular}{|c|c|c|c|c|}
\hline \multirow{2}{*}{$\begin{array}{c}\text { Arthropod } \\
\text { species }\end{array}$} & No. of examined & \multicolumn{2}{|c|}{ Infection of cats } \\
\cline { 3 - 4 } Ct. felis & Age groups & 10 & 9 & Percentage (\%) \\
\cline { 2 - 4 } felis & Kittens (<6 months) & 26 & 22 & $90 \%$ \\
\cline { 2 - 4 } & Adult (>6 months) & 36 & 31 & $84.61 \%$ \\
\hline \multirow{2}{*}{ D. cati } & Overall & 10 & 1 & $86 \%$ \\
\cline { 2 - 4 } & Kittens (<6 months) & 26 & 3 & $10 \%$ \\
\cline { 2 - 4 } & Adult (>6 months) & 36 & 4 & $11.53 \%$ \\
\hline \multirow{2}{*}{ L. serrata } & Overall & 10 & 1 & $11 \%$ \\
\cline { 2 - 4 } & Kittens (<6 months) & 26 & 4 & $15 \%$ \\
\cline { 2 - 4 } & Adult (>6 months) & 36 & 5 & $14 \%$ \\
\hline
\end{tabular}




\section{S.A. Rahman and others}
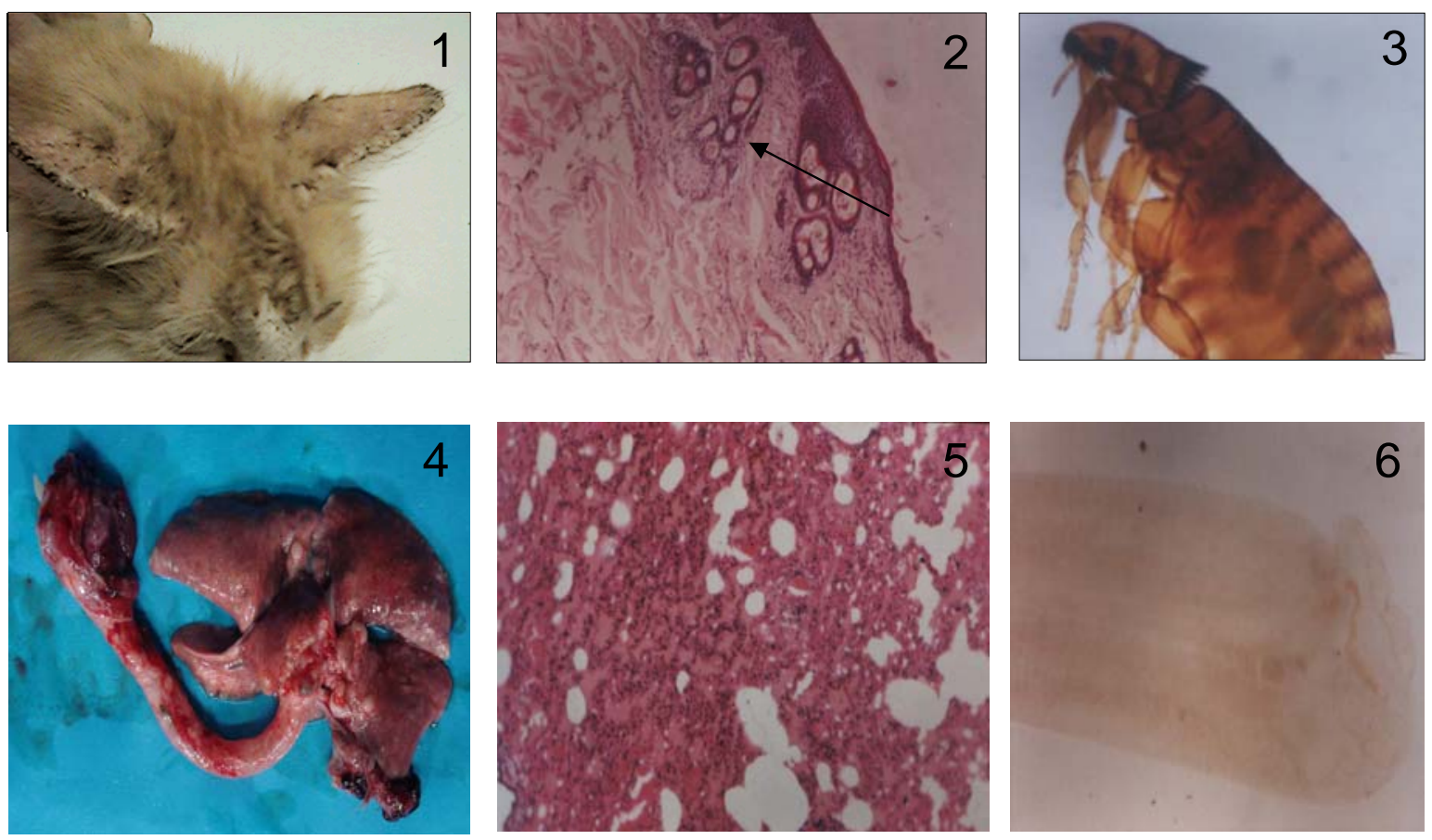

Figure: 1. Alopecia and scab formation on the skin of neck and ear in a cat infested with $D$. cati 2. Demodectic mange on the skin: Section of mite (arrow) 3. Ct. felis felis collected from the skin of a cat 4. Hemorrhage and congestion in the lungs of a cat 5 . Interstitial pneumonia in the lungs of a cat 6 . Anterior portion of adult $L$. serrata showing four prominent hooks.

In all cases females had slightly higher rate (Ct. felis felis, 90\%, D. cati 15\% and L. serrata, 15\%) of infestation than males (Ct. felis felis, 81.25\%, D. cati, 6.25\% and L. serrata, 12.5\%). The odds ratio of females against males was 2.07 in case of Ct. felis felis infestation (Table 3). These finding are very difficult to compare due to unavailability of enough related literature in cats. However, Shimada et al. (2003) showed that Ixodes nipponensis infection was more frequent in castrated male cats in Japan. The exact causes of similar sex prevalence of arthropods are unknown but it may be due to equal body resistance of both the males and females.

Table 3. Sex prevalence of Ct. felis felis, D. cati and L. serrata in the cats of Bangladesh

\begin{tabular}{|c|c|c|c|c|c|}
\hline \multirow{2}{*}{$\begin{array}{c}\text { Arthropod } \\
\text { species }\end{array}$} & \multirow{2}{*}{ No. of examined } & \multicolumn{2}{|c|}{ Infection of cats } & \multirow{3}{*}{ Odds Ratio } \\
\cline { 4 - 5 } & Sex & cats & Number & Percentage (\%) & 2.07 (Female vs. \\
\hline \multirow{3}{*}{ Ct. felis felis } & Male & 16 & 13 & $81.25 \%$ & Male) \\
\cline { 2 - 5 } & Female & 20 & 18 & $90 \%$ & \\
\cline { 2 - 5 } & Overall & 36 & 31 & $86 \%$ & \\
& Male & 16 & 1 & $6.25 \%$ & \\
\cline { 2 - 5 } & Female & 20 & 3 & $15 \%$ & \\
\cline { 2 - 5 } & Overall & 36 & 4 & $11 \%$ & \\
\hline \multirow{3}{*}{ L. serrata } & Male & 16 & 2 & $12.5 \%$ & \\
\cline { 2 - 5 } & Female & 20 & 3 & $15 \%$ & \\
\cline { 2 - 5 } & Overall & 36 & 5 & $14 \%$ & \\
\hline
\end{tabular}


Ct. felis felis infestation was higher in winter season (93.75\%) compared to summer (81.82\%) and rainy (77.77\%) season. Similarly, D. cati infestation was more in winter season (12.5\%) followed by rainy $(11.11 \%)$ and summer (9.09\%) season. Whereas, L. serrata infection was much higher in summer (27.27\%) followed by rainy (11.11\%) and winter season (6.25\%) (Table 4). These findings suggest that there is little seasonal influence on arthropod infestation in cats. Akucewich et al. (2002) found more count of Ct. felis in June and July than in August and September in the USA. Cruz et al. (2001) determined more flea infestation in spring, summer and autumn than in winter. In the experimental areas, temperature ranged from $15^{\circ} \mathrm{C}$ (winter) to $35^{\circ} \mathrm{C}$ (summer); humidity was about $99 \%$ in July and 36\% in December and the soil was silty and loamy. The differences in temperature and humidity year round and soil type could have contributed to the variation in the prevalence of arthropods.

Table 4. Seasonal prevalence of Ct. felis felis, D. cati and L. serrata in the cats of Bangladesh

\begin{tabular}{|c|c|c|c|c|}
\hline \multirow{2}{*}{$\begin{array}{c}\text { Arthropod } \\
\text { species }\end{array}$} & No. of examined & \multicolumn{2}{|c|}{ Infection of cats } \\
\cline { 2 - 4 } Ct. felis & Season of the year & cats & Number & Percentage (\%) \\
\cline { 2 - 4 } & Summer (March to June) & 11 & 9 & $81.82 \%$ \\
\cline { 2 - 4 } & Rainy (July to October) & 9 & 7 & $77.77 \%$ \\
\cline { 2 - 4 } & Winter (Nov. to Feb.) & 16 & 15 & $93.75 \%$ \\
\hline \multirow{4}{*}{ D. cati } & Overall & 36 & 31 & $86 \%$ \\
\cline { 2 - 4 } & Summer (March to June) & 11 & 1 & $9.09 \%$ \\
\cline { 2 - 4 } & Rainy (July to October) & 9 & 1 & $11.11 \%$ \\
\cline { 2 - 4 } & Winter (Nov. to Feb.) & 16 & 2 & $12.5 \%$ \\
\hline \multirow{4}{*}{ L. serrata } & Overall & 36 & 3 & $11 \%$ \\
\cline { 2 - 4 } & Summer (March to June) & 11 & 1 & $27.27 \%$ \\
\cline { 2 - 4 } & Rainy (July to October) & 9 & 1 & $11.11 \%$ \\
\cline { 2 - 4 } & Winter (Nov. to Feb.) & 16 & 5 & $6.25 \%$ \\
\hline
\end{tabular}

In fecal examinations, egg of L. serrata was not found. According to Hobmaeir and Hobmaier (1940), the eggs do not appear in the feces of the dog but instead are found in the nasal secretions. The possibility that the eggs of small number of Linguatula organisms were not shed in the feces of the cats. This aspect requires additional verification.

The present study suggests that arthropod infestation especially Ct. felis felis is highly prevalent in domestic and stray cats in Bangladesh. Besides, it has been found that age, sex and season had little effect on arthropod parasitism. In this research work, arthropod prevalence and pathologic changes in domestic and stray cats are studied. So, further study is essential to investigate regional arthropod prevalence, pathogen carriage and public health significance of cat arthropods in Bangladesh.

\section{REFERENCES}

1. Akucewich LH, Philman K, Clark A, Jillespie J, Kunkle G, Nicklin CF and Greiner EC (2002). Prevalence of ectoparasites in a population of feral cats from north central Florida during the summer. Veterinary Parasitology 109 (1/2): 129-139.

2. Altas MG and Tasan E (1999). Ecto- and endoparasites of cats in rural districts of Elazg and their importance for public health. Saglk Bilimleri Dergisi, Firat Universitesi 13 (3): 233-242.

3. Bowman DD (2000). Respiratory System Parasites of the Dog and Cat (Part I): Nasal Mucosa and Sinuses, and Respiratory Parenchyma. In: Companion and Exotic Animal Parasitology, (Ed. Bowman DD). International Veterinary Information Service (www.ivis.org). New York, USA.

4. $\quad$ 4. Cable RM (1957). An Illustrated Laboratory Manual of Parasitology. $4^{\text {th }}$ edn., Burges Publishing Co., Minneapolis 15, Minnesota, USA.

5. Chowdhury MUA and Dewn ML (1967). Immature linguatulosis in a Murrah buffalo. Pakistan Journal of Veterinary Science 1(2) : 73-75. 


\section{S.A. Rahman and others}

6. Coman BJ, Jones EH and Driesen MA (1981). Helminth parasites and arthropods of feral cats. Australian Veterinary Journal 57(7): 324-7.

7. Cruz VC, Castro GE, Parada FM and Ramos PM (2001). Seasonal occurrence of Ctenocephalides canis (Siphonaptera: Pulicidae) infesting dogs and cats in an urban area in Cuernavaca, Mexico. Journal of Medical Entomology 38(1): 111113.

8. Hendrix C N and Robinson E (2006). Diagnostic Parasitology for Veterinary Technicians. $6^{\text {th }}$ edn., Mosby Inc, Elsevier. pp 252-253.

9. Hobmaeir A and Hobmaier M (1940). On the life cycle of Linguatula rhinaria. American Journal of Tropical Medicine and Hygiene 20:190-210.

10. Jacobs DE (1985). Public Health Significance of Animal Parasites. In: World Animal Science, B2, Parasites, Pests and Predators. (ed. Gaafar SM, Howard WE and Marsh RE) Elsevier Science Pub. pp. 125-126.

11. 11. Jones TC, Hunt RD and King NW (1996). Veterinary Pathology. $6^{\text {th }}$ edn., Williams and Wilkins Co. pp. 549-680.

12. Kelly P, Rolain JM and Raoutt D (2005). Prevalence of human pathogens in cat and dog fleas in New Zealand. New Zealand Medical Journal 118 (1226): 1754.

13. Koutinas AF, Papazahariadou MG, Rallis TS, Tzivara NH and Himonas CA (1995). Flea species from dogs and cats in northern Greece: environmental and clinical implications. Veterinary Parasitology 58(1-2): 109-15.

14. Luna LG (1968). Manual of Histologic Staining Methods of the Armed Forces Institute of Pathology. $3^{\text {rd }}$ edn., Mc Graw Hill Book Co., New York.

15. Rahman M H, Soliman KN and Shaikh H (1971). A preliminary study on the occurrence of Linguatula serrata in street dogs of Bangladesh. Bangladesh Veterinary Journal 5(1-4): 65-69.

16. Rahman MH, Mondal MMH and Huq S (1980). On the occurrence of Linguatula serrata nymphs in goats and cattle of Bangladesh. Bangladesh Veterinary Journal 14(4): 41-42.

17. Rataj AV, Posedi J and Bidovec A (2004). Ectoparasites: Otodectes cynotis, Felicola subrostrtus and Notoedres cati in the ear of cats. Slovenian Veterinary Research 41(2): 89-92.

18. Samad MA, Rahman A and Hossain MI (1979). Studies on demodectic mange in cattle. Bangladesh Journal of Scientific Research 2: 7-13.

19. Schlesselman J J (1982). Case Control Studies. Oxford University Press., New York. pp. 174-177.

20. Shaikh H and Huq MM (1984). Zoonotic Parasites of Bangladesh. Bangladesh Agricultural Research Council. City Press, Mymensingh. pp. 14-15.

21. Shaw SE, Kenny MJ, Tasker S and Birtles RJ (2004). Pathogen carriage by the cat flea Ctenocephalides felis (Bouche) in the United Kingdom. Veterinary Microbiology 102(3-4): 183-8.

22. Shimada Y, Inokuma H, Beppu T, Okuda M and Onishi T (2003). Survey of ixodid tick species on domestic cats in Japan. Veterinary Parasitology 111(2-3): 231-9.

23. Sotiraki ST, Koutinas AF, Leontides LS, Adamama-Moraitou KK and Himonas CA (2001). Factors affecting the frequency of ear canal and face infestation by Otodectes cynotis in the cat. Veterinary Parasitology 96(4): 309-15.

24. Soulsby EJL (1982). Helminths, Arthropods and Protozoa of Domesticated Animals. $7^{\text {th }}$ edn., Bailliere Tindall., London. pp. 35-740.

25. Thoday KL (1979). Skin diseases of dogs and cats transmissible to man. In Practice I: 5- 15.

26. Thrushfield M (1995). Veterinary Epidemiology. $2^{\text {nd }}$ edn., Blackwell Science, USA. pp. 39-41.

27. Vecchio L and Abramo F ( 1999). A case of feline demodectic mange. Quaderni di Dermatologia Supplemento della rivista Veterinaria 4(2): 7-9.

28. Visser M, Rehbein S and Wiedemann C. (2001). Species of flea (siphonaptera) infesting pets and hedgehogs in Germany. Journal of Veterinary Medicine and Infectious Diseases 48(3): 197-20.

29. Wall R and Shearer D (1997). Veterinary Entomology. $1^{\text {st }}$ edn., Chapman and Hall Pub., London. 